\title{
Effectiveness of a course in the control of tobacco use for university health students: A quasi-experimental community intervention trial
}

\author{
Daniel Fernandez, Antonio Molina, Vicente Martin, Beatriz Ordas, Jose Manuel De Luis
}

Leon University Hospital, University of Leon, Leon, Spain

Email: danifega@gmail.com

Received 12 March 2013; revised 13 April 2013; accepted 15 May 2013

Copyright (C) 2013 Daniel Fernandez et al. This is an open access article distributed under the Creative Commons Attribution License, which permits unrestricted use, distribution, and reproduction in any medium, provided the original work is properly cited.

\begin{abstract}
Introduction: The aim of the study was to evaluate the effectiveness of a tobacco control course in the reduction of prevalence and the improvement of knowledge and attitudes among university health students. Method: Quasi-experimental study on a community based intervention. Interventional campus students received a tobacco control course in the first year of the degree. Data were collected by SelfAnswered Questionnaire during three academic years in two graduations years among health students in both campuses. Results: $84.4 \%$ of students participated in the study. In both campuses tobacco use was reduced, not significantly, above all in those joining courses from origins other than baccalaureate. In the intervention and control campus showed an increase in the nicotine dependency according to Fagerström test and a little change in motivation according to Richmond test. The regression model best explaining the improving of the knowledge included academic course mainly and campus and academic background too. With regard to opinions and beliefs tobacco use was not influenced, being associated in general to the academic course. Conclusions: A specific tobacco control course did not change prevalence of tobacco, nicotine dependence and motivation to give up. The improvement in knowledge was associated with academic course in both campuses. We recommend to commence smoking cessation strategies in university health students.
\end{abstract}

Keywords: Tobacco; Students; Nursing; University; Intervention

\section{INTRODUCTION}

The prevention and control of tobacco consumption is a major challenge for health science professionals, for it affects their effectiveness as promoters of health with regard to, among other things, giving up smoking. Their period as students is an optimal time to intervene in the knowledge of these professionals, and in their belief systems and attitudes regarding tobacco [1-3]. Indeed, the correct training at university leads to health professionals developing interventions effective against tobacco use [4-8]. In Spain, students of health sciences are not normally the subject of studies on tobacco consumption, such studies that have been made relying on small populations [9-15]. In general, the prevalence and distribution of smokers among students of health sciences vary by country and the duration of studies [16,17]. Few interventions, however, have been carried out to establish the most effective strategies for a positive influence on their future roles as health promoters and to reduce the tobacco use [16,18-20], especially those who smoke [21].

\subsection{Purpose}

The aim of our study was to assess the effectiveness of a specific training course on tobacco use on the reduction of the prevalence of consumption and on the improvement of knowledge and attitudes among health science students. Thus this is the aim of our study, we hypothesized that the active engagement with the topics of our specific training course on tobacco addiction would reduce the tobacco use and lead to a change in smokingrelated attitudes and behaviors.

\section{METHOD}

Quasi-experimental community intervention trial. The target population comprised all the students enrolled in the first year of Nursing and Physiotherapy at the School of Health Sciences of the University of León at its campuses in León (Nursing) and Ponferrada (Nursing 
and Physiotherapy) in the years 2005-2006 and 20062007. Both courses have a total duration of three years. The students at Ponferrada (the intervention campus) attended a specific training course on tobacco addiction, while those at León (the control campus) did not. Although the impact of Law 28/2005, which came into effect on the 1st January 2006, was not studied, one of its articles deals with measures on health education and assistance in cessation of the smoking habit [22].

The intervention consisted in a free course of 45 hours carrying 4.5 credits. The aim was to improve knowledge, belief and attitudes towards tobacco use and to stress health professionals' position as role models in its control, prevention and treatment. The students carried out related activities like the preparation of leaflets and posters in groups: some focused on cessation and others on advice against starting. Role-play was used for diagnosing smokers and for minimal advice.

We used an anonymous questionnaire designed according to the European Regional Office of the World Health Organization [23] and validated in previous studies $[13,14]$. collection was performed among all the students enrolled in Nursing and Physiotherapy at the University of León during practical laboratory sessions in October 2005, May 2007 and May 2008 for those graduating in 2008; and October 2006, May 2008 and May 2009 for those finishing in 2009. At the time of data collection, a total of 440 students were enrolled.

A smoker was defined as anyone smoking daily (at least one cigarette) or occasionally (less than one cigarette per day) at the time of the survey, while those who had never smoked or who were abstinent were classed as non-smokers. Factors taken into account for smokers were age on starting, nicotine dependence as measured by the Fagerström test (potential range $0-10$ ) and motivation for cessation according to the Richmond test (potential range $0-10$ ). Information was also collected on age, sex, year of study and previous studies.

Knowledge of the consequences of smoking was measured by means of a question requiring the student to identify the link between tobacco use and certain health problems on the following scale:

1) Tobacco use is the main cause of illness.

2) Tobacco use is one of the main causes of illness.

3) There is no link between tobacco use and illness.

4) I don't know if there is a link.

Likewise, another question with the same scale was used for the students to identify the link between air polluted with tobacco smoke and a list of health problems. Those answering 1 or 2 (main cause and one more cause) scored 1 (positive event), those answering 3 (no link) scored -1 (negative event) and those answering 4 , were given a 0 (neutral event). The study group considered the respondent to have "sufficient knowledge" of the first question for scores of 7 and above, and of the second question for scores of 5 or above.

Students' opinions and beliefs were measured on a scale from $1-4$, where $1=$ totally disagree, $2=$ partly agree, $3=$ mostly agree and $4=$ totally agree. On the basis of this, the average was calculated for each of the items measured.

\subsection{Data Analysis}

The Epiinfo for Windows program was used for statisticcal analysis of the data. On the bivariate level, for categorical variables we used the Chi-square test while for continuous variables we applied the T-test in the event of normality for variances as shown by the Wilcoxon test, and the Kruskall-Wallis non-parametric test where there was no such homogeneity. On the multivariate level, we used a logistic regression model including the variables associated with tobacco use with a p-value less than 0.20 . Changes in percentages, both in consumption prevalence and in students with sufficient knowledge, were calculated from the percentage of difference with regard to the first year, which was used as base 100 .

\subsection{Ethical Considerations}

Principles of informed consent and confidentiality were observed during the data collection. The students were assured that their participation or non-participation would in no way affect their academic progress. The study, financed by the Carlos III Health Research Fund of the Spanish Ministry of Health and Consumption, was approved by the Ethics Committee of the University of León.

\section{FINDINGS}

\subsection{Description of Participants}

$84.8 \%(373 / 440)$ of the students took part in the study, whose characteristics as found in the first survey, along with their distribution by group and intervention, are shown in Table 1, which also reveals that those in the intervention group were younger and included more males than the controls, and that no differences were observed between the two groups in tobacco consumption prevalence or in the age when they started smoking.

\subsection{History of Tobacco Use}

On both campuses there was a drop in the prevalence of smokers from the first to the second year, $8 \%$ on the intervention campus and $4 \%$ on the control one (Table 2). These decreases were observed mainly among students with a background other than the baccalaureate, prevalence increasing among those who had studied the baccalaureate, in both groups (Table 2). 
Table 1. Distribution of the participants in the first year of the university health science courses.

\begin{tabular}{ccccc}
\hline \multirow{2}{*}{ Sex } & & Control Campus (173) & Intervention Campus (200) & p \\
& Men & $10.4 \%(18)$ & $17.5 \%(35)$ & 0.06 \\
Academic background & Women & $89.6 \%(155)$ & $82.5 \%(165)$ & 0.34 \\
Baccalaureate & Others & $68.2 \%(118)$ & $63.5 \%(127)$ & 0.82 \\
Graduation year & $2005-08$ & $31.8 \%(55)$ & $36.5 \%(73)$ & 0.04 \\
Age & $2006-09$ & $46.8 \%(81)$ & $48 \%(96)$ & 0.85 \\
Age of smokers & Average (SD) & $53.2 \%(92)$ & $20.7(4.3)$ & 0.61 \\
Age of non smokers & Smokers & $19.9(3.3)$ & $28.0 \%(56)$ & 0.08 \\
Ageo on starting to smoke & Average (SD) & $27.2 \%(47)$ & $21.6(3.7)$ & 0.95 \\
\hline
\end{tabular}

Table 2. Distribution of prevalences by campus, year of study, academic background and total per campus

\begin{tabular}{ccccccccccccc}
\hline & \multicolumn{3}{c}{ CONTROL CAMPUS } & \multicolumn{5}{c}{ INTERVENTION CAMPUS } \\
\hline & \multicolumn{1}{c}{ Baccalaureate } & \multicolumn{2}{c}{ Non Baccalaureate } & \multicolumn{2}{c}{ TOTAL } & \multicolumn{2}{c}{ Baccalaureate } & \multicolumn{2}{c}{ Non Baccalaureate } & \multicolumn{2}{c}{ TOTAL } \\
\hline & $\%$ & Change & $\%$ & & $\%$ & Change & $\%$ & Change & $\%$ & Change & $\%$ & Change \\
\hline $\mathbf{1}^{\circ}$ & 21.2 & & 40 & & 27.2 & & 25.2 & & 32.9 & & 28.0 & \\
$\mathbf{2}^{\circ}$ & 23.9 & +12.7 & 37.1 & -7.2 & 28.1 & +3.3 & 29.4 & +14.2 & 21.3 & -35.2 & 26.3 & -6.1 \\
$\mathbf{3}^{\circ}$ & 21.4 & +0.94 & 35.6 & -11 & 26.1 & -4.0 & 28.1 & +11.5 & 21.1 & -35.8 & 25.7 & -8.2 \\
\hline
\end{tabular}

Of the smokers, 248 (84.6\%) had started before beginning their university studies and 45 (15.4\%) took up the habit during their studies, giving an initiation incidence of $5.1 \%(45 /[1126-248])$. In this regard, there were no statistical differences by campus or year of study, but there were differences according to academic background, 33 students $(5.5 \%$ or $33 /[736-144])$ with the baccalaureate taking up the habit in comparison with 12 $(4.2 \%$ or $12 /[390-104])$ from other backgrounds $(p=$ $0.05)$. Differences in nicotine dependence according to the Fagerström test were found between the campuses, with the control campus showing an average of $3.6+2.2$ and the intervention campus $2.6+2.1(\mathrm{p}=0.0001)$ in the pre-course survey. Dependence rose on both campuses (Table 3). No differences were observed in motivation to stop as measured by the Richmond test either at the beginning of the study or during the students' time at university (Table 3).

\subsection{Knowledge}

With regard to knowledge of the effects of tobacco on health, in the pre-intervention survey, more students at the intervention campus had a sufficient level of knowl-
Table 3. Distribution of averages for the Fagerström nicotine dependence test and the Richmond test for motivation for cessation organized by campus and year of study.

\begin{tabular}{ccccccc}
\hline & & \multicolumn{2}{c}{$\begin{array}{c}\text { Control } \\
\text { Campus }\end{array}$} & \multicolumn{2}{c}{$\begin{array}{c}\text { Intervention } \\
\text { Campus }\end{array}$} \\
\hline & & Average & SD & Average & SD & p \\
\cline { 2 - 6 } $\begin{array}{c}\text { Fagerström } \\
\text { Test }\end{array}$ & 1st & 3.4 & 2.1 & 2.3 & 2.2 & 0.01 \\
& 2nd & 3.4 & 2.4 & 2.4 & 2.2 & 0.03 \\
& 3rd & 4.1 & 2.0 & 3.0 & 2.1 & 0.01 \\
& 1st & 5.2 & 2.4 & 5.4 & 2.7 & - \\
$\begin{array}{c}\text { Richmond } \\
\text { Test }\end{array}$ & 2nd & 4.4 & 2.3 & 4.8 & 2.5 & - \\
& 3rd & 5 & 2.6 & 4.8 & 3.2 & - \\
\hline
\end{tabular}

edge $(64.5 \%$ vs $53.8 \% ; p=0.03$, Table 4$)$. On both campuses the percentage rose as their studies progressed, although the percentage remained higher on the intervention campus (Table 4). From the logistic regression analysis, which included all the variables studied, the model best explaining the prevalence of sufficient knowledge included the variables of year of study, campus and academic background. Thus, third-year students, 
Table 4. Distribution of the prevalence of "sufficient knowledge" regarding health problems and tobacco use organized by campus and year of study.

\begin{tabular}{cccccccc}
\hline & \multicolumn{3}{c}{ CONTROL Campus $^{*}$} & \multicolumn{4}{c}{ INTERVENTION Campus $^{*}$} \\
\hline & $\mathrm{n} / \mathrm{N}$ & $\%$ & Change & $\mathrm{n} / \mathrm{N}$ & $\%$ & Change & $\mathrm{p}$ \\
\hline 1st & $93 / 173$ & 53.8 & & $129 / 200$ & 64.5 & 0.03 & \\
2nd & $153 / 196$ & 78.1 & $\mathbf{+ 4 5 . 1}$ & $172 / 194$ & 88.7 & $\mathbf{+ 3 7 . 5}$ & 0.005 \\
3rd & $156 / 176$ & 88.6 & $\mathbf{+ 6 4 . 7}$ & $180 / 187$ & 96.3 & $\mathbf{+ 4 9 . 3}$ & 0.005 \\
\hline
\end{tabular}

${ }^{*} \mathrm{p}<0.0001$.

students on the intervention campus and those from a non-baccalaureate background registered differences of 9.1, 1.9 and 1.9 with regard respectively to first-year students, controls and those with a baccalaureate background $(\mathrm{p}<0.001)$.

Smokers on the control campus with sufficient knowledge increased from $61.7 \%$ in the first year to $84.8 \%$ in the third $(\mathrm{p}<0.001)$, with a corresponding increase on the intervention campus from $75 \%$ to $97.9 \%(p<0.001)$. Among non-smokers, the respective increases were from $50 \%-8 \%$ to $90 \%(\mathrm{p}<0.001)$ and from $60.4 \%$ to $95 \%$ $7 \%(\mathrm{p}<0.001)$.

Regarding knowledge of the link between environmental smoke and health problems, significant differences were observed between the two campuses as early as the first interview, these differences persisting in the second interview and losing statistical significance in the third year (Table 5). Logistic regression analysis revealed ORs of 8, 2.2 and 1.5 for the intervention campus, third year and non-baccalaureate background with regard to the control campus, first year and baccalaureate background.

\subsection{Beliefs Concerning Tobacco Addiction}

Table 6 shows students' average degree of agreement on opinions concerning tobacco use. Students' year of study has a statistically significant influence at both campuses except regarding the item "Smokers take your recommendations into account", where there was a statistical increase on the intervention campus $(\mathrm{p}<0.0018)$, but not on the control one. For the statements "Students should receive specific training regarding tobacco use" and "Topics concerning prevention should be included in the training" there were statistical differences in the last year, with a higher average on the control campus. The bivariate analysis revealed no differences in averages concerning consumption, sex or academic background.

\section{DISCUSSION}

The educational intervention carried out reduced the percentage of tobacco addiction in comparison with the control campus, but without statistical significance, to an ex- tent similar to studies performed in other countries [1820]. Among our students the greatest decrease was among those from non-baccalaureate backgrounds, which suggests a greater effectiveness among this section of the population.

The intervention had no effect on nicotine dependence levels, which rose on both campuses in the way described by Boccoli [25]. The low initial dependence levels as compared with those recorded in similar studies concerning health science students [4,21,26-28] may have hindered the good results of the intervention, together with the fact that it was not designed for this end. Likewise, the intervention did not alter motivation to cease as measured by the Richmond test, which showed a minimal change on both campuses.

As in previous studies [12,21,28-30], most of the students smoked before coming to university and the number of new smokers was similar on the two campuses. Follow-up studies would, however, be useful to determine the exact incidence of new smokers.

Although improved knowledge is significantly associated with both the intervention and the years of study, the latter seemed to be the most important factor, with ORs near to 9 .

The effect of the intervention, despite reaching an OR approaching 2, was weakened by the knowledge acquired during their studies. Whether students were smokers or nonsmokers had no significant influence, unlike other studies, where tobacco use was a determining factor [12,21,31].

The year of study had a significant influence on all items in the section on opinions and beliefs, except number 2 , where there was no modification on the intervenetion campus, whereas on the other, probably owing to the intervention, as students were taught the importance they would have as future health professionals on the control of tobacco use.

For Sections 4 and 6, the average degree of agreement in the third year was higher on the control campus, perhaps because students on the intervention campus do not perceive these aspects as necessary. This study revealed no differences in knowledge, attitudes and beliefs between smokers and non-smokers on either campus, un- 
Table 5. Distribution of students with "sufficient knowledge" of the link between health problems and air polluted by tobacco smoke, organized by campus and year of study.

\begin{tabular}{ccccccccc}
\hline & \multicolumn{3}{c}{ CONTROL Campus $^{*}$} & \multicolumn{3}{c}{ INTERVENTION Campus $^{*}$} & \\
& $\mathrm{n} / \mathrm{N}$ & $\%$ & Change & $\mathrm{n} / \mathrm{N}$ & $\%$ & Change & \\
1st & $83 / 172$ & 48,3 & & $130 / 199$ & 65,3 & & $<0,0001$ \\
2nd & $143 / 196$ & 73 & $+\mathbf{5 1 . 1}$ & $172 / 192$ & 89.6 & $+\mathbf{3 7 . 3}$ & $<0.0001$ \\
3rd & $156 / 176$ & 88.6 & $\mathbf{+ 8 3 . 4}$ & $174 / 187$ & 93 & $\mathbf{+ 4 2 . 4}$ & 0.14 \\
\hline
\end{tabular}

${ }^{*} \mathrm{p}<0.0001$.

Table 6. Distribution of average of students' degree of agreement at the beginning and end of the period of study.

\begin{tabular}{|c|c|c|c|c|c|c|c|}
\hline & \multicolumn{3}{|c|}{ CONTROL CAMPUS } & \multicolumn{3}{|c|}{ INTERVENTION CAMPUS } & \multirow[b]{2}{*}{$\mathbf{p}^{* *}$} \\
\hline & 1ST & 3RD & $\mathbf{p}^{*}$ & 1ST & 3RD & $\mathbf{p}^{*}$ & \\
\hline $\begin{array}{l}\text { 1. Health professionals } \\
\text { should be role models. }\end{array}$ & $2.50 \pm 0.83$ & $3.25 \pm 0.71$ & $<0.0001$ & $2.37 \pm 1$ & $3.27 \pm 0.72$ & $<0.0001$ & $\begin{aligned} 1^{\circ} \mathrm{p} & =0.193^{\circ} \\
\mathrm{p} & =0.76\end{aligned}$ \\
\hline $\begin{array}{l}\text { 2. Smokers heed our } \\
\text { recommendatioins }\end{array}$ & $2.45 \pm 0.78$ & $2.60 \pm 0.77$ & 0.15 & $2.34 \pm 0.69$ & $2.60 \pm 0.75$ & 0.0018 & $\begin{aligned} 1^{\circ} \mathrm{p} & =0.143^{\circ} \\
\mathrm{p} & =0.98\end{aligned}$ \\
\hline $\begin{array}{l}\text { 3. My knowledge allows me to } \\
\text { give correct information on the } \\
\text { consequences of tobacco use. }\end{array}$ & $2.69 \pm 0.86$ & $3.19 \pm 0.60$ & $<0.0001$ & $2.52 \pm 0.86$ & $3.09 \pm 0.66$ & $<0.0001$ & $\begin{aligned} 1^{\circ} \mathrm{p} & =0.063^{\circ} \\
\mathrm{p} & =0.12\end{aligned}$ \\
\hline $\begin{array}{l}\text { 4. Students should receive } \\
\text { specific training regarding } \\
\text { tobacco consumption }\end{array}$ & $2.59 \pm 1.08$ & $3.60 \pm 0.56$ & $<0.0001$ & $2.49 \pm 1.14$ & $3.32 \pm 0.65$ & $<0.0001$ & $\begin{array}{r}1^{\circ} p=0.423^{\circ} \\
p<0.0001\end{array}$ \\
\hline $\begin{array}{l}\text { 5. I know strategies and } \\
\text { methods for helping people } \\
\text { to give up. }\end{array}$ & $2.05 \pm 0.76$ & $2.76 \pm 0.82$ & $<0.0001$ & $1.92 \pm 0.81$ & $2.71 \pm 0.85$ & $<0.0001$ & $\begin{aligned} 1^{\circ} \mathrm{p} & =0.123^{\circ} \\
\mathrm{p} & =0.52\end{aligned}$ \\
\hline $\begin{array}{l}\text { 6. Topics concerning } \\
\text { prevention should be included } \\
\text { in our courses }\end{array}$ & $2.56 \pm 0.95$ & $3.52 \pm 0.57$ & $<0.0001$ & $2.47 \pm 1$ & $3.21 \pm 0.70$ & $<0.0001$ & $\begin{array}{r}1^{\circ} \mathrm{p}=0.423^{\circ} \\
\mathrm{p}<0.0001\end{array}$ \\
\hline
\end{tabular}

"p: analysis on comparing 1st \& 3rd years; ${ }^{* *}$ p: analysis on comparing 1 st \& 3 rd years on the control and intervention campuses.

like most studies carried out among health science students $[9,10,15,24,29,32-35]$, where consumption did have an influence regarding these sections.

\section{CONCLUSIONS}

The specific training course on tobacco use carried out does not appear to alter the overall prevalence of consumption among students of nursing and physiotherapy.

Among those with a non-baccalaureate background, consumption decreased in a statistically significant way, $35 \%$ in comparison with the first year. The intervention did not influence nicotine dependence or motivation to give up. Improved knowledge of tobacco use is strongly linked to their education, less to their background and to the intervention on the intervention campus.

Opinions and beliefs were not affected by tobacco use or by the specific course, but did improve with year of study. The results reveal the need to initiate strategies for cessation of the habit among health science students and set up anti-smoking programmes in the years immediately prior to university in order to reduce or delay the onset of the habit.

\section{REFERENCES}

[1] Lenz, B.K. (2008) Beliefs, knowledge, and self-efficacy of nursing students regarding tobacco cessation. American Journal of Preventive Medicine, 35, 494-500. doi:10.1016/j.amepre.2008.09.004

[2] International Council of Nurses (1999) Tobacco use and health: Position statement. ICN, Geneve.

[3] Rice, V. and Stead, L. (2001) Nursing interventions for smoking cessation. The Cochrane Database of Systemic Reviews. doi:10.1002/14651858.CD001188

[4] Patkar, A.A., Hill, K., Batra, V., Vergare, M.J. and Leone, F.T. (2003). A comparison of smoking habits among medical and nursing students. Chest, 124, 1415-1420. 
doi:10.1378/chest.124.4.1415

[5] Canton, J.C., Baker, L.C. and Hughes, R.G. (1993) Preparedness for practice: Young physicians' view of their professional education. Journal of the American Medical Association, 270, 1035-1040. doi:10.1001/jama.1993.03510090019005

[6] Richmond, R.L., Keohe, L. and Webster, I.W. (1993) Multivariate models for predicting abstention following intervention to stop smoking by general practitioner. Addiction, 88, 1127-1135. doi:10.1111/j.1360-0443.1993.tb02132.x

[7] Wewers, M.E., Kidd, K., Armbruster, D. and Sarna, L. (2004) Tobacco dependence curricula in U.S. baccalaureate and graduate nursing education. Nursing Outlook, 52, 95-101.

[8] Kraatz, E.S., Dudas, S., Frerichs, M., Paice, J. and Swenson, C. (1998) Tobacco-related instruction in undergraduate nursing education in Illionois. Journal of Nursing Education, 37, 415-417.

doi:10.1016/j.outlook.2003.09.007

[9] Cordón Granados, F., Jauma Pou, R.M., Vallescar Piñana, R., Ribo Bonet, C. and Martín Mateo, M. (1992) Smoking habits in nursing students: Prevalence, attitudes and knowledge. Gaceta Sanitaria, 6, 58-61. doi:10.1016/S0213-9111(92)71093-0

[10] Heras Tébar, A., García Sanchón, C., Hernández López, M.C., Ballestín, N. and Nebot, M. (1997) Smoking among nursing students in Catalonia: Knowledge, attitudes and practice. Gaceta Sanitaria, 11, 267-273. doi:10.1016/S0213-9111(97)71306-2

[11] Mas, A., Nerín, I., Barrueco, M., Cordero, J., Guillén, D., Jiménez-Ruiz, C. and Sobradillo, V. (2004) Smoking habits among sixth-year medical students in Spain. Archivos de Bronconeumología, 40, 403-408. doi:10.1016/S0300-2896(04)75559-3

[12] Fernández García, D., Martin Sánchez, V., Vázquez Casares, A.M., Liébana Presa, C., Fernández Martínez, M.E. and De Luis González, J.M. (2007) Tobacco use amongst nursing and physiotherapy students: A cross sectional questionnaire survey. International Journal of Nursing Studies, 44, 780-785. doi:10.1016/j.ijnurstu.2006.02.008

[13] Molina, A.J., Fernández, D. and Martin, V. (2009) Sensitivity and specificity of a selfadministered questionnaire of tobacco use including Fagerstrom test. International Journal of Nursing Studies, 47, 181-189. doi:10.1016/j.ijnurstu.2009.05.022

[14] Martín, V., Fernández, D., Ordoñez, C., Molina, A.J., Fernández, M.E. and De Luis, J.M. (2008) Valoración de la prevalencia de consumo de tabaco en estudiantes de primer curso de ciencias de la salud con tres métodos diferentes. Revista Española de Salud Pública, 82, 221229. doi:10.1590/S1135-57272008000200008

[15] Pericas, J., González, S., Bennasar, M., De Pedro, J., Aguiló, A. and Bauzá, L. (2009) Cognitive dissonance towards the smoking habit among nursing and physiotherapy students at the University of Balearic Islands in Spain. International Nursing Review, 56, 95-101. doi:10.1111/j.1466-7657.2008.00669.x
[16] Rowe. K. and Clark, J.M. (2000) The incidence of smoking amongst nurses: A review of the literature. Journal Advanced of Nursing, 31, 1046-1053. doi:10.1046/j.1365-2648.2000.01391.x

[17] Smith, D.R. (2007) A systematic review of tobacco smoking among nursing students. Nurse Education in Practice, 7, 293-302. doi:10.1016/j.nepr.2006.09.003

[18] Hope, A., Kelleher, C.C. and O'Connor, M. (1998) Lifestyle practices and the health promotion environment of hospital nurses. Journal Advanced of Nursing, 28, 438447. doi:10.1046/j.1365-2648.1998.00791.x

[19] Sejr, H.S. and Osler, M. (2002) Do smoking and health education influence student nurses' knowledge, attitudes and professional behavior? Preventive Medicine, 34, 260-265. doi:10.1006/pmed.2001.0981

[20] Rapp, K., Büchele, G., Jähnke, A.G. and Weiland, S.K. (2006) A cluster-randomized trial on smoking cessation in German student nurses. Preventive Medicine, 42, 443448. doi:10.1016/j.ypmed.2006.03.006

[21] Chalmers, K., Seguire, M. and Brown, J. (2002) Tobacco use and baccalaureate nursing students: A study of their attitudes, beliefs and personal behaviours. Journal of Advanced Nursing, 40, 17-24. doi:10.1046/j.1365-2648.2002.02336.x

[22] Galán, I. and López, M.J. (2009) Tres años con Ley de medidas sanitarias frente al tabaquismo: Aire más limpio, pero no lo suficiente. Gaceta Sanitaria, 23, 87-90. doi:10.1016/j.gaceta.2009.01.003

[23] World Health Organization \& Regional Office for Europe (2002) European strategy for tobacco control. WHO, Copenhagen.

[24] Rowe, K. and Clark, J.M. (1999) Evaluating the effecttiveness of a smoking cessation intervention designed for nurses. International Journal of Nursing Studies, 36, 301-311. doi:10.1016/S0020-7489(99)00024-3

[25] Boccoli, E., Federici, A., Melani, A. and DePoala, E. (1996) Results of a questionnaire about nurse students' smoking habits and knowledge in an Italian teaching school of nursing. European Journal of Epidemiology, 12, 1-3. doi:10.1007/BF00144419

[26] Suzuki, K., Ohida, T., Yokoyama, E., Kaneita, Y. and Takemura, S. (2005) Smoking among Japanese nursing students: Nationwide survey. Journal of Advanced Nursing, 49, 268-275. doi:10.1111/j.1365-2648.2004.03291.x

[27] Kitajima, T., Ohida, T., Harano, S., Kamal, A., Takemura, S., Nozaki, N., et al. (2002) Smoking behavior, initiating and cessation factors among Japanese nurses: A cohort study. Public Health, 116, 347-352.

[28] Fernandez, D., Martin, V., Molina, A.J. and De Luis, J.M. (2010) Smoking habits of students of nursing: A questionnaire survey (2004-2006). Nurse Education Today, 30, 480-484. doi:10.1016/j.nedt.2009.10.012

[29] Clark, E., McCann, T.V., Rowe, K. and Lazenbatt, A. (2004) Cognitive dissonance and undergraduate nursing students' knowledge of, and attitudes about, smoking. Journal of Advanced Nursing, 46, 586-594. doi:10.1111/j.1365-2648.2004.03049.x

[30] Sekijima, K., Seki, N. and Suzuki, H. (2005) Smoking 
prevalence and attitudes toward tobacco among student and staff nurses in Niigata, Japan. Tohoku Journal of Experimental Medicine, 206, 187-194. doi:10.1620/tjem.206.187

[31] Baron-Epel, O., Josephsohn, K. and Ehrenfeld, M. (2004) Nursing students' perceptions of smoking prevention. Nurse Education Today, 24, 145-151. doi:10.1016/j.nedt.2003.11.001

[32] Adams, A., Bell, P.F. and Pelletier, S.D. (1994) Nurses and smoking: A comparative study of students of nursing and teaching. Australian Health Review, 17, 84-101.

[33] Melani, A.S., Verponziani, W., Boccoli, E., Trianni, G.L., Federici, A., Amerini, R., et al. (2000) Tobacco smoking habits, attitudes and beliefs among nurse and medical students in Tuscany. European Journal of Epidemiology, 16, 607-611. doi:10.1023/A:1007697126844

[34] Ohida, T., Kamal, A., Takemura, S., Sone, T., Minowa, M. and Nozaki, S. (2001) Smoking behaviour and related factors among Japanese nursing students: A cohort study. Preventive Medicine, 32, 341-347. doi:10.1006/pmed.2001.0828

[35] McCann, T.V. and Rowe, K. (2005) Undergraduate nursing students' attitudes toward smoking health promotion. Nursing and Health Sciences, 7, 164-174. doi:10.1111/j.1442-2018.2005.00228.x 